\title{
Thyroid hormones modulate the endocrine and autocrine/paracrine actions of leptin on thyrotropin secretion
}

\author{
M A L Costa da Veiga, K de Jesus Oliveira, F H Curty and \\ C C Pazos de Moura \\ Laboratório de Endocrinologia Molecular, Instituto de Biofísica Carlos Chagas Filho, CCS-BlocoG-Cidade Universitária, Ilha do Fundão, 21949.900 Rio de \\ Janeiro, Brazil \\ (Requests for offprints should be addressed to C C Pazos de Moura; Email: maveiga@biof.ufrj.br)
}

\begin{abstract}
We investigated the influence of hypo- and hyperthyroidism on the ability of leptin to modulate TSH secretion. Two hours after receiving leptin $(8 \mu \mathrm{g}$ leptin/100 g BW; s.c.), hyperthyroid rats $(10 \mu \mathrm{g}$ thyroxine (T4)/100 g body weight (BW) for 5 days) showed a $1 \cdot 7$-fold increase in serum TSH $(P<0 \cdot 05)$; in hypothyroid rats, leptin had no effect. Hemi-pituitaries of hyperthyroid rats incubated with $10^{-9}$ and $10^{-7} \mathrm{M}$ leptin showed reductions in TSH release of 40 and $50 \%$ respectively $(P<0 \cdot 05)$; incubation with 1:2000 and 1:500 dilutions of antiserum against leptin resulted in 3 - and 4 -fold higher TSH release $(P<0 \cdot 05$
\end{abstract}

and $P<0.001$ respectively). However, in hypothyroid pituitaries leptin or the antiserum had no effect. The results suggest that the in vivo and in vitro responsiveness of TSH to leptin is abolished in hypothyroidism and is preserved in short-term hyperthyroidism, in comparison to previous reports in euthyroidism. In addition, the inhibitory action of pituitary leptin is enhanced in hyperthyroid glands, which may suggest a role for locally produced leptin in the suppression of TSH release associated with hyperthyroidism.

Journal of Endocrinology (2004) 183, 243-247

\section{Introduction}

Leptin is a hormone secreted mainly by adipocytes which decreases caloric intake and increases energy expenditure (Ahima et al. 2000, Korbonits 1998). In addition, leptin is an important neuroendocrine regulator, including regulation of the hypothalamus-pituitary-thyroid axis. It is well known that states of malnutrition are associated with a reduction in leptin production and thyroid axis activity. In fasting rats, replacement doses of leptin partially avoided the reduction of hypothalamic thyrotropin-releasing hormone (TRH) content, serum thyrotropin (TSH) and thyroid hormone concentrations induced by fasting (Ahima et al. 1996, Seoane et al. 2000). Also in humans, the marked suppression of TSH secretion induced by $72 \mathrm{~h}$ fasting was blunted with replacement doses of leptin, although leptin treatment did not reverse the fastinginduced changes in serum triiodothyronine (T3) and reverse T3 (rT3; Chan et al. 2003). Therefore, in states of nutritional deficiency the decrease in leptin contributes significantly to the reduction of thyroid hormone production, which represents an important adaptative mechanism aiming to reduce energy expenditure. The same may be occurring in some cases of euthyroid sick syndrome. It has been reported that among elderly patients with chronic non-thyroidal illnesses, those who presented low serum free thyroxine (T4) and free T3 - as well as high reverse T3 - also had low concentrations of serum leptin (Corsonello et al. 2000). In addition, hypothyroid patients may show decreased serum leptin (Valcavi et al. 1996), although there is some disagreement in published reports (Zimmermann-Belsing et al. 2003) and so far a consistent relationship between serum concentrations of leptin and thyroid hormone has not been established.

Leptin may also be involved in modulating the set point of the thyroid axis under physiological conditions. Genetic leptin deficiency, both in rodents and humans, is not always associated with decreased thyroid hormone levels, but mild central hypothyroidism in children has been reported (Clément et al. 1998) as well as a stimulatory effect of leptin therapy on thyroid axis secretion (Faroqui et al. 2002). In addition, in normally fed rats, acute injection of low doses of leptin, was able to increase TSH secretion (Ortiga-Carvalho et al. 2002). The stimulatory effect of leptin on TSH release is probably due to positive regulation of TRH production and release by leptin (Ahima et al. 1996, Legradi et al. 1997), since we had shown before that the direct effect of leptin on the rat pituitary is to inhibit TSH release (Ortiga-Carvalho et al. 2002). Therefore, at least in rats, the augmentation of TSH secretion induced by acute administration of leptin is related to its hypothalamic action. 
In addition to regulating TSH secretion by acting as a circulating hormone, leptin may also exert an autocrine/ paracrine action within the anterior pituitary. Support for this mechanism is given by the presence of leptin, its receptor and their mRNAs in human and murine pituitary cells, including thyrotrophs (Morash et al. 1999, Jin et al. 2000, McDuffie et al. 2004). Furthermore, the immunoneutralization of pituitary-produced leptin, by adding leptin antiserum to the incubation medium of isolated pituitaries, led to an increase in TSH release (OrtigaCarvalho et al. 2002). Therefore, these data strongly suggest that locally produced pituitary leptin acts as a local TSH-releasing inhibitor.

Thyroid hormones are the most important physiological inhibitors of TSH secretion. The strong negative regulation of thyroid hormones on TSH and TRH production and release determines the set point of the hypothalamicpituitary-thyroid axis. Altered states of thyroid function are able to change the response of thyrotrophs to TRH and other regulators (DeLean et al. 1977, Gurr \& Kourides 1985) and in the present work, we investigated whether hypo-and hyperthyroid rats exhibit changes in endocrine and local leptin actions on TSH release.

\section{Materials and Methods}

\section{Animals}

Adult male Wistar rats (270-300 g body weight (BW)) were kept under $12 \mathrm{~h}$ light: $12 \mathrm{~h}$ darkness cycle (light onset at $0700 \mathrm{~h}$ ) at $24 \pm 1{ }^{\circ} \mathrm{C}$; a standard diet and tap water were available ad libitum. All experimental protocols were approved by our institutional animal care committee (CAUAP).

The in vivo and in vitro experiments were performed with hypo- and hyperthyroid rats. Hypothyroidism was induced by treatment with methimazole $(0.03 \%)$ in the drinking water for 21 days, as previously described (Engler et al. 1982). Hyperthyroidism was induced by s.c. daily single injections of thyroxine (T4-L-Thyroxine, Sigma), $10 \mu \mathrm{g} / 100 \mathrm{~g} \mathrm{BW}$ for 5 days. The rats exhibited moderate hyperthyroidism, with T4 serum concentrations around $55 \%$ higher than euthyroid rats $(3 \cdot 27 \pm 0.1$ vs $5 \cdot 04 \pm$ $0.6 \mu \mathrm{g} / \mathrm{dl}$ ); serum T3 around $28 \%$ higher than normal rats $(85.8 \pm 1 \cdot 2$ vs $110.9 \pm 8.6 \mathrm{ng} / \mathrm{dl})$ and serum TSH levels reduced to approximately $25 \%$ of those of euthyroid rats $(0.51 \pm 0.04 \mathrm{vs} 1.83 \pm 0.1 \mathrm{ng} / \mathrm{ml})$. With this short-term treatment with $\mathrm{T} 4$ we aimed to block predominantly the release of TSH and avoid more profound chronic effects of thyroid hormone on thyrotrophs.

\section{In vivo experiments}

Hypo- and hyperthyroid animals were divided in two groups that received a single s.c. injection of saline (control group) or $8 \mu \mathrm{g} / 100 \mathrm{~g}$ BW mouse recombinant leptin (National Hormone Pituitary Program (NHPP), NIH, Torrance, CA, USA). The rats were killed by decapitation $2 \mathrm{~h}$ after the injection. The time was chosen based on our previous report on euthyroid animals (OrtigaCarvalho et al. 2002). Serum was obtained from trunk blood to measure TSH. Animals were killed before $1100 \mathrm{~h}$

\section{In vitro experiments}

Hypo- and hyperthyroid animals were killed by decapitation and their anterior pituitaries were quickly dissected out. Each hemi-pituitary was immediately transferred to a flask containing $1 \mathrm{ml}$ Krebs-Ringer bicarbonate medium $(\mathrm{pH} 7 \cdot 4)$ at $37{ }^{\circ} \mathrm{C}$ in an atmosphere of $95 \% \mathrm{O}_{2}: 5 \% \mathrm{CO}_{2}$ in a Dubnoff metabolic shaker. After a 30-min preincubation period, medium was changed to $1 \mathrm{ml}$ medium alone (control) or medium containing mouse recombinant leptin to a final concentration of $10^{-11}, 10^{-9}$ or $10^{-7} \mathrm{M}$. At the end of $2 \mathrm{~h}$ incubation an aliquot was removed for TSH measurement.

In another set of experiments, using the same in vitro system, hemi-pituitaries were incubated in the presence of antiserum against leptin (rabbit anti-mouse leptin; NHPP) at $1: 2000$ or 1:500 dilutions. Control hemi-pituitaries were incubated with normal rabbit serum (NRS) at 1:500 dilution. After $2 \mathrm{~h}$, an aliquot of medium was removed to measure TSH levels.

\section{Hormone measurements}

TSH concentration in the serum and in the incubation medium was measured by specific RIA, employing reagents supplied by NHPP as previously described (OrtigaCarvalho et al. 1996, Chard 1987), and was expressed in terms of the reference preparation (RP3). Within-assay variation was $7 \cdot 7 \%$. The minimum assay detection value was $0.36 \mathrm{ng} / \mathrm{ml}$. Serum T4 was detected by RIA (T4 Mab-ICN Pharmaceuticals, Costa Mesa, CA, USA) and within-assay variation was $1 \cdot 4 \%$.

\section{Statistical analyses}

Data are reported as means \pm S.E.M. One-way ANOVA followed by a Student-Newman-Keuls multiple comparisons test was employed for assessment of significance of all data except for serum TSH, which was analyzed by ANOVA only after logarithmic transformation (Zar 1996). Differences were considered to be significant at $P<0 \cdot 05$.

\section{Results}

\section{In vivo experiments}

Hyperthyroid animals killed $2 \mathrm{~h}$ after receiving a single injection of leptin $(8 \mu \mathrm{g} / 100 \mathrm{~g} \mathrm{BW})$ showed a $1 \cdot 7$-fold 


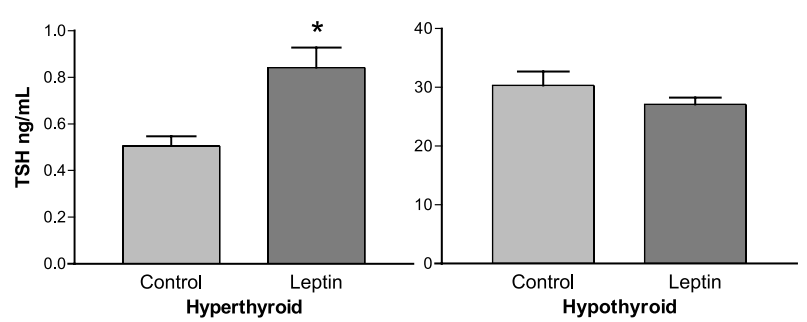

Figure 1 Serum TSH concentration in hyper- and hypothyroid rats, $2 \mathrm{~h}$ after a single s.c. injection of mouse recombinant leptin $(8 \mu \mathrm{g} / 100 \mathrm{~g} \mathrm{BW})$ or saline (Control). Data are presented as means \pm S.E.M. ${ }^{*} P<0 \cdot 01$ vs control; $n=12$ animals for hyperthyroid and 6-7 animals for hypothyroid per group.

higher serum TSH $(P<0 \cdot 01)$ than the saline-injected group. However, in hypothyroid animals, leptin administration was ineffective in changing serum TSH (Fig. 1). Serum T4 concentrations of saline-treated and leptin groups respectively, were similar in hypothyroid $(2 \cdot 4 \pm 0 \cdot 11 \mathrm{vs} 2 \cdot 2 \pm 0 \cdot 11 \mu \mathrm{g} / \mathrm{dl})$ and hyperthyroid rats $(5 \cdot 0 \pm 0.59$ vs $6 \cdot 2 \pm 0 \cdot 94 \mu \mathrm{g} / \mathrm{dl})$.

\section{In vitro experiments}

Leptin-incubated hemi-pituitary glands from hyperthyroid animals showed a dose-dependent decrease in TSH release, statistically significant at $10^{-9}$ and $10^{-7} \mathrm{M}$ $(P<0 \cdot 05)$, with a reduction of approximately $60 \%$ for both groups. However, leptin was not able to significantly change TSH release from glands of hypothyroid rats as compared with hypothyroid ones incubated with medium alone (Fig. 2).

In hyperthyroid hemi-pituitaries, incubation with antiserum against leptin at 1:2000 and 1:500 dilutions for $2 \mathrm{~h}$ resulted in approximately 3 - and 4-fold increases in TSH release respectively, as compared with the group incubated with 1:500 dilution of NRS $(P<0 \cdot 05$ and $<0 \cdot 001$ respect-

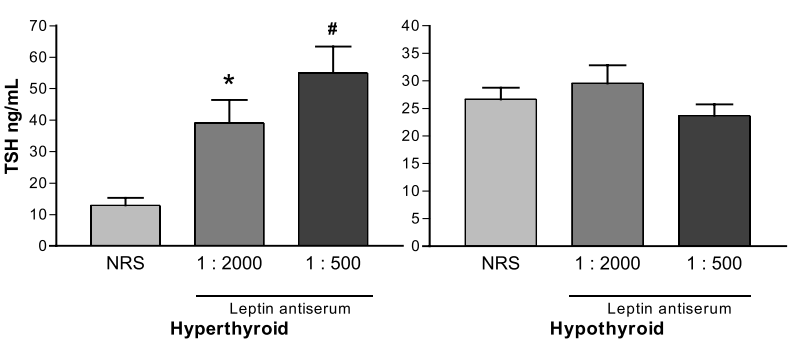

Figure 3 TSH release from hemi-pituitary glands of hyper- and hypothyroid rats incubated with NRS at 1:500 dilution (Control) or in the presence of antiserum against mouse recombinant leptin at 1:2000 and 1:500 dilutions for 2 h. Data are means \pm S.E.M. ${ }^{*} P<0 \cdot 05, \# P<0 \cdot 001$ vs control; $n=10-12$ hemi-pituitaries for hyperthyroid and 11 hemi-pituitaries for hypothyroid per group.

ively). On the other hand, hemi-pituitaries from hypothyroid rats showed no response to the antiserum anti-leptin incubation (Fig. 3).

\section{Discussion}

The present study shows that leptin action on TSH secretion is modulated by thyroid function. In hypothyroidism the acute stimulatory effect of leptin on TSH release, previously reported in euthyroidism (OrtigaCarvalho et al. 2002) could not be observed. This is in agreement with the report of Seoane et al. (2000), which showed that leptin was not able to stimulate TSH release in hypothyroid fasting rats. This is probably related to the already high rates of TSH secretion in hypothyroid rats that could not be further increased by acute leptin administration. Another possibility is that the cellular response to leptin may be changed at the level of the receptor or at the post-receptor level, resulting in resistance to leptin action.

However, in hyperthyroid animals the stimulatory effect of leptin on TSH secretion, although modest, is still

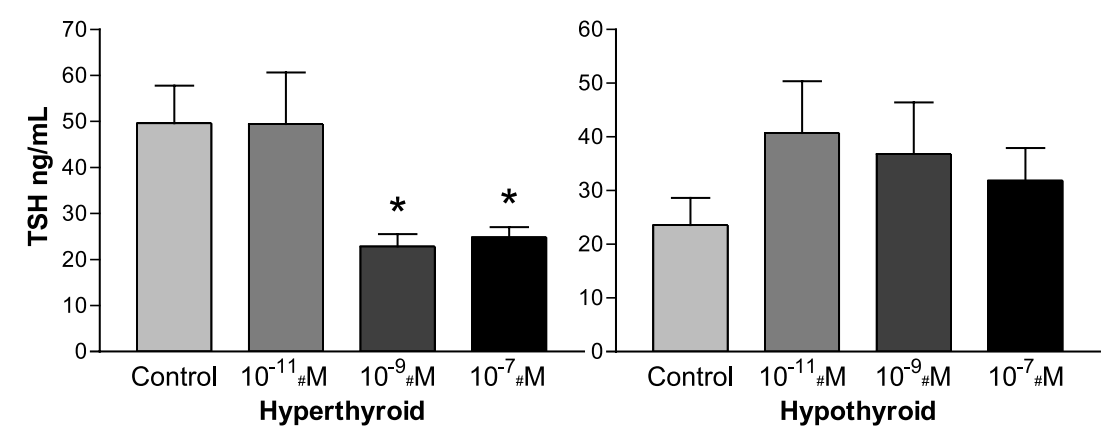

Figure 2 TSH release from hemi-pituitary glands of hyper- and hypothyroid rats incubated in the absence (Control) or presence of mouse recombinant leptin at different concentrations for $2 \mathrm{~h}$. Data are presented as means \pm S.E.M. ${ }^{*} P<0 \cdot 05$ vs control; $n=7-8$ hemi-pituitaries for hyperthyroid and 9-11 hemi-pituitaries for hypothyroid per group. 
present. Even though the animals presented a mild, short-term hyperthyroidism, with TSH partially suppressed, this finding highlights the potency of leptin action on TSH release. The fact that serum T4 was similar in hyperthyroid groups treated with saline or leptin shows that the results are not due to changes in thyroid hormone serum levels. Leptin is probably acting at the hypothalamus, directly or indirectly stimulating TRH release, which in turn stimulates TSH secretion since the direct pituitary effect of leptin on TSH release is inhibitory, as shown by the in vitro results. Therefore, it can be suggested that the acute rise in serum leptin was able to override the potent inhibitory effect of thyroid hormones on TRH release. However, it is likely that with a chronic and higher degree of hyperthyroidism leptin would not be able to change TSH release because of the profound effects of thyroid hormone reducing not only the release but mostly the synthesis of TRH and TSH.

In agreement with in vivo studies, hemi-pituitaries from hypothyroid rats did not respond significantly to leptin, in regard to TSH release. In contrast, the direct pituitary effect of leptin on TSH release, previously reported in euthyroid glands, is maintained in hyperthyroid hemi-pituitaries. Although direct comparison is difficult, it seems that the magnitude of the leptin-induced rise in TSH release was slightly higher in hyperthyroid glands than that reported previously for euthyroid glands (OrtigaCarvalho et al. 2002). Therefore, the direct action of leptin on TSH release is modified by thyroid hormones; hypothyroidism is associated with decreased or abolished responsiveness to leptin while hyperthyroidism seems to increase it.

In addition, thyroid status also modulated the action of pituitary leptin as an autocrine/paracrine regulator of TSH secretion, as suggested by the in vitro responses to the antiserum against leptin. In glands from hypothyroid rats, the antiserum had no effect, while in hyperthyroidism the increase in TSH release in the presence of the antiserum was higher than that observed for euthyroid glands. This can be deduced by comparing data from a previous report, in which the increase in TSH release from euthyroid pituitaries required a 4-fold higher concentration of the antiserum anti-leptin (Ortiga-Carvalho et al. 2002). The data suggest that endogenous leptin has a more important inhibitory action at hyperthyroid pituitaries than at euthyroid ones. This enhanced action of an inhibitory local factor may be contributing to the suppression of TSH release present in hyperthyroidism. Other important local TSH-releasing inhibitors, such as the bombesin-like peptide, neuromedin B has its effect regulated by thyroid state. Thyroid hormones act to increase the pituitary neuromedin B, expression (Jones et al. 1992, OrtigaCarvalho et al. 1996), and probably release, which may explain the higher response to the immunoneutralization of the peptide (Rettori et al. 1992). However, it is not known if thyroid hormones are able to modulate leptin or leptin receptor expression at the pituitary. This is a feasible hypothesis since pituitary leptin has been shown to be positively regulated by estrogen and growth-hormonereleasing hormone when added together to rat pituitary cell cultures (McDuffie et al. 2004).

Although we had used low dilutions of the antiserum against leptin, the physiological relevance of locally produced leptin on TSH release is supported by the fact that the antiserum action was dilution dependent and its effect was the opposite of that of leptin itself. Future studies will be necessary to determine the importance of pituitary leptin in relation to circulating leptin in the physiological regulation of TSH release.

Therefore, here we extended our previous observations in the euthyroid state to hypo- and hyperthyroid states, showing that the in vivo stimulatory effect of leptin on TSH release is still present in short-term hyperthyroidism, but disappears in hypothyroidism. In addition, thyroid state also modulates TSH responsiveness to direct pituitary leptin action that is abolished in hypothyroidism. Moreover, the action of pituitary leptin as a local inhibitor of TSH release also disappears in hypothyroidism and is enhanced in hyperthyroidism. The modulation of pituitary leptin action by thyroid hormones, the most important physiological inhibitor of TSH release, reinforces the hypothesis that pituitary leptin acts as a local regulator, modulating or fine-tuning the action of thyroid hormones on $\mathrm{TSH}$ release.

\section{Acknowledgements}

The authors thank Dr A Parlow, National Pituitary Program (NIDDK) for kindly providing us with the recombinant mouse leptin and antiserum against leptin. This research was supported by CNPq, CAPES and FAPERj.

\section{References}

Ahima RS, Prabakaran D, Mantzoros C, Qu D, Lowell B, Maratos-Filer E \& Flier JS 1996 Role of leptin in the neuroendocrine response to fasting. Nature 382 250-252.

Ahima RS, Saper CB, Flyer JS \& Elmquist JK 2000 Leptin regulation of neuroendocrine systems. Frontiers in Neuroendocrinology 21 263-307.

Chan JL, Heist K, DePaoli AM, Veldhuis JD \& Mantzoros CS 2003 The role of falling leptin levels in the neuroendocrine and metabolic adaptation to short-term starvation in healthy men. Journal of Clinical Investigation 111 1409-1421.

Chard T 1987 An introduction to radioimmunoassay and related techniques. In Laboratory Techniques in Biochemistry and Molecular Biology, pp 1-74. Eds RH Burdon \& PH van Kiniooenberg. Amsterdam: Elsevier Science.

Clément K, Vaisse C, Lahlou N, Cabrol S, Pelloux V, Cassuto D, Gourmelen M, Dina C, Chambaz J, Lacorte JM, Basdevant A, Bougneres P, Lebouc Y, Froguel P \& Guy-Grand B 1998 A mutation in the human leptin receptor gene causes obesity and pituitary dysfunction. Nature 392 398-401. 
Corsonello A, Buremi M, Artemisia A, Giorgianni G, Mauro VN \& Corica F 2000 Plasma leptin concentrations in relation to sick euthyroid syndrome in elderly patients with nonthyroidal illnesses. Gerontology 46 64-70.

DeLean A, Ferland L \& Drouin J 1977 Modulation of pituitary thyrotropin-releasing hormone receptor levels by estrogens and thyroid hormones. Endocrinology 100 1496-1504.

Engler H, Taurog A \& Nakashima T 1982 Mechanism of inactivation of thyroid peroxidase by thioureylene drugs. Biochemical Pharmacology 31 3801-3806.

Faroqui IS, Matarase G, Lord GM, Keogh JM, Lawrence E, Agwu C, Sanna V, Jebb S, Perna F, Fontana S, Lechler R, DePaoli A \& O'Rahilly S 2002 Beneficial effects of leptin on obesity. T cell hyporesponsiveness, and neuroendocrine/metabolic dysfunction of human congenital leptin deficiency. Journal of Clinical Investigation 110 1093-1103.

Gurr JA \& Kourides IA 1985 Thyroid hormone regulation of thyrotropin alpha- and beta-subunit gene transcription. DNA 4 301-307.

Jin L, Zhang S, Burguera BG, Couce ME, Osamura RY, Kulig E \& Lloyd RV 2000 Leptin and leptin receptor expression in rat and mouse pituitary cells. Endocrinology 141 333-339.

Jones PM, Withers DJ, Ghatei MA \& Bloom SR 1992 Evidence for neuromedin $\mathrm{B}$ synthesis in the rat anterior pituitary gland. Endocrinology 130 1829-1836.

Korbonits M 1998 Leptin and the thyroid - a puzzle with missing pieces. Clinical Endocrinology 49 569-572.

Legradi G, Emerson CH, Ahima RS, Flier JS \& Lechan RM 1997 Leptin prevents fasting-induced suppression of prothyrotropin releasing hormone messenger ribonucleic acid in neurons of the hypothalamic paraventricular nucleus. Endocrinology 138 2569-2576.

McDuffie IA, Akhter N \& Childs G V 2004 Regulation of leptin mRNA and protein expression in pituitary somatotropes. Journal of Histochemistry and Cytochemistry 52 263-273.
Morash B, Li A, Murphy PR, Wilkinson M \& Ur E 1999 Leptin gene expression in the brain and pituitary gland. Endocrinology 140 5995-5998.

Ortiga-Carvalho TM, Polak J, McCann S \& Pazos-Moura CC 1996 Effect of thyroid hormones on pituitary neuromedin B and possible interaction between thyroid hormones and neuromedin B on thyrotropin secretion. Regulatory Peptides 67 47- 53.

Ortiga-Carvalho TM, Oliveira KJ, Soares BA \& Pazos-Moura CC 2002 The role of leptin in the regulation of TSH secretion in the fed state: in vivo and in vitro studies. Journal of Endocrinology 174 121-125.

Rettori V, Pazos-Moura CC, Moura EG, Polak J \& McCann SM 1992 Role of neuromedin B in the control of the release of thyrotropin in hypothyroid and hyperthyroid rats. PNAS $\mathbf{8 9}$ 3035-3039.

Seoane LM, Carro E, Tovar S, Casanueva FF \& Dieguez C 2000 Regulation of in vivo TSH secretion by leptin. Regulatory Peptides $\mathbf{9 2}$ 25-29.

Vacalvi RM, Zini M, Peino R, Casanueva FF \& Dieguez C 1996 Influence of thyroid status on serum immunoreactive leptin levels. Journal of Clinical Endocrinology and Metabolism $\mathbf{8 2}$ 1632-1634.

Zar JH 1996 Data Transformations - Biostatistical Analysis, 3rd edn, pp 277-279. London: Prentice Hall International.

Zimmermann-Belsing T, Brabant G, Holst JJ \& Feldt-Rasmussen U 2003 Circulating leptin and thyroid dysfunction. European Journal of Endocrinology 149 257-271.

Received in final form 7 July 2004

Accepted 8 July 2004 